\title{
Algal bioactive compounds reduce net oxygen fluxes of artificial diatom biofilms
}

\author{
J. Leflaive ${ }^{1}$, E. Buffan-Dubau ${ }^{2}$, L. Ten-Hage ${ }^{1, *}$ \\ ${ }^{1}$ Laboratoire d'Ecologie Fonctionnelle (EcoLab), UMR 5245 CNRS/UPS/INPT, Université Paul Sabatier, bât 4R3, \\ 118 route de Narbonne, 31062 Toulouse Cedex 09, France \\ ${ }^{2}$ Laboratoire d'Ecologie Fonctionnelle (EcoLab), UMR 5245 CNRS/UPS/INPT, Université Paul Sabatier, 29 rue Jeanne Marvig,
} 31055 Toulouse Cedex 04, France

\begin{abstract}
A wide range of chemicals are exuded by microalgae or released by grazed cells. In biofilms, these bioactive compounds may potentially exert a large effect on growing cells, since the cellular density is high and intercellular distances are short. We studied whether such compounds affect the functioning of the biofilm and, therefore, we tested several compounds. These included eicosapentaenoic acid (EPA) and 2E,4E-decadienal (DD), which are produced during grazing on diatoms. In addition, we obtained a mixture of compounds by methanolic extraction of the allelopathic green alga Uronema confervicolum. We studied how the net oxygen production rates of an artificial diatom biofilm were affected by the different compounds. The extracts of $U$. confervicolum significantly reduced these rates. Unexpectedly, EPA had a strong effect on the oxygen production rates in the biofilm. A toxic effect was also observed in ecotoxicological assays with the diatom Nitzschia palea. However, the inhibitory effect of DD on the biofilm was weaker than that of EPA, while DD was shown to be more toxic in liquid culture. This differential effect on liquid culture and biofilms indicates that the organization of benthic algae in biofilm should be considered when studying chemical interactions between these organisms.
\end{abstract}

KEY WORDS: Diatom biofilms · Eicosapentaenoic acid · Decadienal · Allelopathy · Oxygen microprofile $\cdot$ Microelectrode $\cdot$ Nitzschia palea

\section{INTRODUCTION}

Phototrophic micro-organisms are under intense competitive pressure for resources, such as space, light or nutrients. Moreover, being the basis of the aquatic food web, microalgae experience high grazing pressure (Sterner 1989). In this context, phototrophic micro-organisms have developed a wide range of mechanisms to increase their chance of survival, including morphological, behavioural and physiological adaptations. One strategy that received much attention recently is the production of allelochemicals (Pohnert et al. 2007), which are secondary metabolites that affect other organisms (Jüttner \& Wu 2000). Prokaryotic and eukaryotic phototrophs are indeed known for their potential to produce a wide variety of compounds, which are not directly implicated in pri- mary metabolism and have various biological activities (Cannell 1993, Patterson et al. 1994). The allelochemicals produced by phototrophic micro-organisms may be used as a defence mechanism (e.g. Wolfe 2000), by acting as either a deterrent (Höckelmann et al. 2004, Jüttner 2005), a toxin (Jüttner 2001, Becher \& Jüttner 2005) or an inhibitor (e.g. Gross 2003, Leflaive \& TenHage 2007). All these defence mechanisms contribute to improving the competitive ability of the producing species by providing negative interference with competitors. The allelochemicals that specifically inhibit the competitors are termed allelopathic compounds (Rice 1984). Other allelochemicals include inhibitory compounds that are released during grazing.

In benthic systems, like phototrophic biofilms, many species coexist (Stevenson 1996), and the competition between organisms is enhanced by reduced 
resource availability and by an extensive overlap in nutritional requirements among species (McCormick 1996). Strategies based on chemical interference have evolved as a consequence of the strong competitive pressure and are favoured by the extracellular polymeric substances (EPS) and the cohesive structure of the biofilm (Jüttner 1999). Thus, benthic micro-organisms may be exposed to a wide range of chemical compounds that are either exuded by neighbouring cells or released during grazing of the benthic microalgae (Liess \& Hillebrand 2004). All these compounds may directly or indirectly affect the phototrophic and heterotrophic components of biofilms in either a positive or a negative way. Hence, we anticipate that the functioning of the whole system is also affected by these compounds. Nevertheless, to our knowledge, few studies have examined the effects of algal compounds on natural benthic microbial communities, although many ecotoxicological studies have focused on the effect of xenobiotic compounds on these communities (Guasch et al. 2002, Berard et al. 2003, Rohr \& Crumrine 2005, Roussel et al. 2007). The aim of the present study was to determine whether some specific algal bioactive compounds may actually modify the functioning of the biofilms. We employed some compounds belonging to 2 classes of allelochemicals: those associated with grazing and those produced by competitors.

Two typical bioactive compounds produced during grazing of diatoms are the eicosapentaenoic acid (EPA), a polyunsaturated fatty acid, and $2 \mathrm{E}, 4 \mathrm{E}$-decadienal (DD), a polyunsaturated aldehyde. Both are produced by the lipoxygenase cascade. Cell damage induces lipase activity, which converts polyunsaturated fatty acids (such as EPA and eicosatetraenoic acid) into hydroperoxy fatty acids that are further transformed into unsaturated aldehydes and $\omega$-oxofatty acids by hydroperoxyde lyases (Pohnert 2000). Some of the unsaturated aldehydes produced by marine diatoms, including $\mathrm{DD}$, are toxic to grazers, notably by impairing their reproduction (Miralto et al. 1999, Ianora et al. 2004). Although most studies concerning such reactive aldehydes focused on marine planktonic diatoms (Casotti et al. 2005, Vardi et al. 2006, Hansen \& Eilersten 2007), high lipoxygenase activities have been detected in freshwater diatomdominated biofilms (Jüttner \& Dürst 1997) and some reactive unsaturated aldehydes (2E, 4Z-heptadienal and $2 \mathrm{E}, 4 \mathrm{E}$-octadienal) have been identified in benthic freshwater diatoms (Wendel \& Jüttner 1996). EPA was acutely toxic to the freshwater anostracan grazer Thamnocephalus platyurus (Jüttner 2001), but had no effect on marine copepods (Miralto et al. 1999). Recently, Casotti et al. (2005) demonstrated that DD could also induce adverse effects in the marine diatom Thalassiosira weissflogii, comprising a modification of membrane permeability, a decrease in growth rate and a decrease of pigment concentration. Moreover, DD could trigger a process showing the signs of programmed cell death, like apoptosis, in mammalian cells. Two other reactive aldehydes, 2E, 4Z-heptadienal and 2E, 4E-octadienal, had similar effects at higher concentrations. Vardi et al. (2006) demonstrated that, in addition to inducing cell death in marine diatoms, DD may act as a stress signal for these algae. These results as a whole led to the hypothesis that the presence of DD, which may be highly concentrated in diatom-dominated biofilms (Jüttner \& Dürst 1997, Jüttner 2005), may have a negative effect on biofilms. The effects of EPA on diatoms have not yet been studied, and contradictory results have been obtained for grazers (Jüttner 2001, Pohnert et al. 2002). Nevertheless, since DD and EPA are produced simultaneously (Pohnert 2002, Jüttner 2005), it should be relevant to determine whether this compound could also have a negative effect on diatomdominated biofilm.

In this study, for comparison, we also considered bioactive compounds produced by algal competitors. We employed a mixture of compounds obtained by methanolic extraction of the benthic/epiphytic green alga Uronema confervicolum. This species produces allelopathic compounds that inhibit the growth of several algae (Leflaive et al. 2008). This species was also chosen because it often co-occurs with diatoms in biofilms. Methanolic extracts of this alga contain compounds that are actively released during growth as well as compounds that are released during cell lysis. The use of this mixture helped to test the hypothesis that the presence of an allelopathic or toxin-producing species may have a negative effect on the functioning of phototrophic biofilms, in addition to its potential effect on biofilm specific composition.

The aim of the study was to determine whether these algal bioactive compounds that are released during grazing of diatoms (i.e. EPA and DD) or through cell lysis/exudation (from U. confervicolum methanolic extracts) (Table 1) may negatively affect the functioning of artificial diatom biofilms. The effect of these compounds was estimated by measuring biofilm oxygen production with a few invasive microelectrode techniques (Glud et al. 1992, Epping et al. 1999). Indeed, a modification of biofilm functioning may affect both phototrophic and heterotrophic activities, leading to modifications of local oxygen concentrations. Relevancy of the method and specificity of algae growing in biofilms were assessed using diuron (3-[3,4-dichlorophenyl]1,1-dimethylurea, photosystem-II inhibitor) as a reference positive control. 
Table 1. Different compounds chosen for studying the effects of algal bioactive compounds on diatom biofilms

\begin{tabular}{|c|c|c|c|c|}
\hline Designation & Compound class & Origin & Effect on other species & Source \\
\hline $\begin{array}{l}\text { Eicosapentaenoic } \\
\text { acid (EPA) }\end{array}$ & $\begin{array}{l}\text { Polyunsaturated } \\
\text { fatty acid }\end{array}$ & $\begin{array}{l}\text { Enzymatic } \\
\text { conversion of } \\
\text { diatom } \\
\text { compounds } \\
\text { during grazing }\end{array}$ & $\begin{array}{l}\text { - Mortality of a freshwater } \\
\text { anostracod } \\
\text { - No effect on marine copepod }\end{array}$ & $\begin{array}{l}\text { Jüttner (2001) } \\
\text { Miralto et al. (1999) }\end{array}$ \\
\hline $\begin{array}{l}\text { 2E, 4E-decadienal } \\
\text { (DD) }\end{array}$ & $\begin{array}{l}\text { Polyunsaturated } \\
\text { aldehyde }\end{array}$ & $\begin{array}{l}\text { Enzymatic } \\
\text { conversion of } \\
\text { diatom } \\
\text { compounds } \\
\text { during grazing }\end{array}$ & $\begin{array}{l}\text { - Insidious effects on marine } \\
\text { copepods } \\
\text { - Negative effects on sea urchin } \\
\text { fecundity } \\
\text { - Repellent effect on freshwater } \\
\text { crustaceans } \\
\text { - Induction of stress and mortality } \\
\text { in marine diatoms }\end{array}$ & $\begin{array}{l}\text { Miralto et al. (1999) } \\
\text { Caldwell et al. (2004) } \\
\text { Jüttner (2005) } \\
\text { Casotti et al. (2005, } \\
\text { Vardi et al. (2006) }\end{array}$ \\
\hline Methanolic extracts & Unknown & $\begin{array}{l}\text { Green algae } \\
\text { Uronema } \\
\text { confervicolum }\end{array}$ & $\begin{array}{l}\text { Growth inhibition of freshwater } \\
\text { diatoms }\end{array}$ & Leflaive et al. (2008) \\
\hline Diuron & Substituted urea & Xenobiotic & Inhibition of photosynthesis & \\
\hline
\end{tabular}

\section{MATERIALS AND METHODS}

Organisms and stock cultures. The green alga Uronema confervicolum, and the diatoms Nitzschia palea (Kützing) W. Smith and Fistulifera saprophila (Lange-Bertalot \& Bonik) Lange-Bertalot were isolated from biofilms sampled in the River Tarn in France. The strains were maintained in $300 \mathrm{ml}$ Erlenmeyer flasks on Combo medium (Kilham et al. 1998) in a temperature controlled chamber at $18^{\circ} \mathrm{C}(16: 8 \mathrm{~h}$ light:dark, $45 \mu \mathrm{mol} \mathrm{m} \mathrm{m}^{-2} \mathrm{~s}^{-1}$ ).

Biofilm cultivation. Biofilms were cultivated from 2 diatom strains, Nitzschia palea and Fistulifera saprophila. N. palea was chosen because it can be grown easily either in liquid culture or in biofilms. Moreover, Nitzschia species are often employed in ecotoxicological assays, notably in anti-biofouling studies (Metaxas \& Lewis 1991, Dobretsov et al. 2004). The addition of a small proportion of F. saprophila, a diatom that produces exopolysaccharides in great quantities (Lange-Berthalot 2001), increased biofilm cohesion. F. saprophila is known to produce EPA (Kitano et al. 1997), but no similar information was found for $N$. palea.

One week before the beginning of the experiments, $200 \mathrm{ml}$ aliquots of dense cultures were centrifuged for $10 \mathrm{~min}$ at $6000 \times g$ to remove the medium and then resuspended in $10 \mathrm{ml}$ of fresh medium. The algae were mixed in 9:1 (Nitzschia palea:Fistulifera saprophila) proportion and $1 \mathrm{ml}$ of this mixture was dropped onto each Petri dish ( $9 \mathrm{~cm}^{2}$ area) filled with $5 \mathrm{ml}$ of $1.5 \%$ of agar Combo medium. The presence of agar medium allowed both biofilm growth and safe use of fragile microelectrodes. The inoculated Petri dishes $(6<\mathrm{n}<$
10) were incubated under the same conditions as for stock cultures. A dense and cohesive biofilm, covered by a few millimetres of culture medium, was formed within a few days.

Allelopathic extracts. Uronema confervicolum was grown in a 51 Erlenmeyer flask, through which air was bubbled, for $2 \mathrm{wk}$ at $18^{\circ} \mathrm{C}(16: 8 \mathrm{~h}$ light:dark, $45 \mu \mathrm{mol}$ $\left.\mathrm{m}^{-2} \mathrm{~s}^{-1}\right)$. Cells were harvested by centrifugation $(6000 \times g, 15 \mathrm{~min})$ and extracted twice in $60 \%$ aqueous methanol. This solvent was chosen to extract a wide range of molecules. The extract was evaporated to dryness, weighted, resuspended in $100 \%$ methanol to a final concentration of $10 \mathrm{mg} \mathrm{ml}^{-1}$ and stored at $-20^{\circ} \mathrm{C}$ until use.

Ecotoxicological tests. This experiment was designed to study the effects of the fatty acid EPA, the unsaturated aldehyde DD, Uronema confervicolum methanolic extracts and the herbicide diuron on Nitzschia palea in liquid cultures. As Fistulifera saprophila formed cohesive films and aggregates in liquid cultures, this diatom was not used for the ecotoxicological tests. The tests were run in triplicate in 96-well microplates, each well containing $200 \mu \mathrm{l}$ of Combo medium inoculated with exponentially growing cultures of $N$. palea at $5 \times 10^{4}$ cells $\mathrm{ml}^{-1}$. The diatom suspensions were exposed to a range of final concentrations of diuron $(0.01,0.02,0.03,0.04,0.05,0.06,0.07$, 0.08 and $0.1 \mu \mathrm{M}), \operatorname{EPA}\left(1,5,10,20,50\right.$ and $\left.100 \mu \mathrm{g} \mathrm{ml}^{-1}\right)$, $\operatorname{DD}\left(0.1,0.25,0.5,0.8,1,2,3,5,8\right.$ and $\left.12 \mu \mathrm{g} \mathrm{m}^{-1}\right)$ and $U$. confervicolum extracts $(10,20,30,40,50,65,80,95$, 110 and $130 \mu \mathrm{g} \mathrm{ml}^{-1}$ ). All chemicals were purchased from Sigma-Aldrich. The plates were incubated for $3 \mathrm{~d}$ under the same conditions used for stock cultures. The growth of $N$. palea in suspensions was determined by 
measurements of optical density (650 nm, multi-well plate reader, Metertech) before addition of the tested compound and every $24 \mathrm{~h}$ during the incubation. Growth rates of $N$. palea were estimated using linear regression over log-transformed optical densities against time. $\mathrm{EC}_{50}$ values (i.e. compound concentration that gave a $50 \%$ reduction in growth rate after $3 \mathrm{~d}$ ) were determined using non-linear regression with the software StatView, version 4.55.

Microelectrode measurements and oxygen flux calculation. Oxygen concentration microprofiles were measured in artificial biofilms using a UNISENSE profiling module equipped with 2 Clark-type $\mathrm{O}_{2}$ microelectrodes (50 $\mu \mathrm{m}$ outside diameter) and a computercontrolled micromanipulator (Revsbech 1989). Twopoint calibrations were performed as described by Revsbech et al. (1983). Oxygen partial pressures were converted to concentrations as a function of temperature and conductivity (Garcia \& Gordon 1992). The vertical spatial resolution of oxygen concentration profiles $(100 \mu \mathrm{m})$ was determined according to Revsbech et al. (1983), taking into account both the oxygen diffusion rate in the biofilm and the external diameter of the microelectrode. The net oxygen metabolism of the biofilm was calculated from each oxygen profile after Kühl et al. (1996). The flux of oxygen between the biofilm and the overlying water was calculated from the oxygen profile in the diffusion boundary layer according to Fick's diffusion law (a positive sign of the flux indicated a flux from the biofilm towards the water and a negative sign indicated a flux from the water towards the biofilm). All the measures were made at a constant temperature of $19^{\circ} \mathrm{C}$ and constant light of $70 \mu \mathrm{mol} \mathrm{m} \mathrm{m}^{-2} \mathrm{~s}^{-1}$.

Short-term experiment. This experiment was designed to study the effects of diuron, EPA, DD and Uronema confervicolum allelopathic extracts on the oxygen metabolism of the cultivated diatom biofilm during a $2 \mathrm{~h}$ exposure. For each compound, 3 to 4 different concentrations (see Fig. 2A) were tested. Before starting the experiments, the biofilms were grown for 1 wk under stock culture conditions (see 'Biofilm cultivation') and randomly chosen biofilms were used as the control biofilms (without the testing compound) and the treatment biofilms (with the testing compound added). Oxygen microprofiles were measured simultaneously at one location in both control and treatment biofilms after a $1 \mathrm{~h}$ acclimation period under the measurement conditions (i.e. after stabilization of the profiles). The compound to be tested was then added at the adequate concentration. Controls received equal amounts of liquid Combo medium to induce a perturbation of the water column equivalent to those created in treatment biofilms by addition of the testing compound. The microprofiles were determined every $15 \mathrm{~min}$ for $2 \mathrm{~h}$, at the same location on each biofilm.
Each pair of control and treatment biofilms used simultaneously for measures was considered as 1 replicate $(3 \leq \mathrm{n} \leq 5)$.

Medium-term experiment. In this experiment the exposure time of the cultivated biofilms to the testing compounds was prolonged. The Petri dishes containing the diatom biofilms were incubated in a culture chamber (at $18^{\circ} \mathrm{C}, 16: 8 \mathrm{~h}$ light:dark, $45 \mu \mathrm{mol} \mathrm{m}{ }^{-2} \mathrm{~s}^{-1}$ ) for 3 d. For each compound, 2 to 3 concentrations were tested (see Fig. 2B). Eight oxygen microprofiles at 8 different locations were measured just before the addition of the compound and at the end of the incubation in each biofilm (treatment and control). By measuring at 8 different locations we were able to take into account spatial heterogeneity. The evolution of mean oxygen flux during each exposure was compared between control and treatment biofilms. The measures were performed simultaneously in 1 control biofilm and 1 treatment biofilm during successive experiments repeated 3 to 5 times. During the incubation, $50 \%$ of the medium was renewed daily for both control and treatments.

Statistical analysis. The evolution of oxygen flux during incubation periods was statistically compared between control and treatment biofilms by running repeated-measure ANOVA with time $(0$ and $2 \mathrm{~h}$ before and $3 \mathrm{~d}$ after exposure to the compounds) and presence of the compound used as the 2 factors (StatView for Windows, version 4.55). For the short-term experiment, the analyses were performed using 1 oxygen flux value from each replicate biofilm and for the medium-term experiment they were performed using the mean oxygen flux values obtained from the 8 microprofiles of each biofilm. Each incubation using 1 compound at 1 concentration was analysed separately since sets of biofilms were prepared at different moments. Linear regressions were performed with the software StatView for Windows. One-way ANOVAs were performed on the differences between 2 successive values of the proportion of the $t_{0}$ oxygen flux (flux before compound addition) of biofilm [100 $\times$ (oxygen flux at $t$ )/(oxygen flux at $t_{0}$ )] for each treatment (1 concentration of 1 compound) of the short-term experiment.

\section{RESULTS}

\section{Compound toxicity}

The $3 \mathrm{~d} \mathrm{EC}_{50}$ values of EPA, DD, Uronema confervicolum extracts and diuron were determined (Table 2). All these compounds reduced Nitzschia palea growth rate. As expected, the higher toxicity was induced by diuron exposures with an $\mathrm{EC}_{50}$ value of $0.093 \mu \mathrm{M}$ $\left(21.7 \mu \mathrm{g} \mathrm{l}^{-1}\right.$ ). Thus, the biofilms treated with diuron 
Table 2. Nitzschia palea. Mean $( \pm \mathrm{SE}) 3 \mathrm{~d} \mathrm{EC}_{50}$ values of the 4 compounds used against the diatom

\begin{tabular}{|lc|}
\hline Compound & \multicolumn{1}{c|}{ EC $_{50}$} \\
\hline Diuron & $0.093 \pm 0.021 \mu \mathrm{M}$ \\
DD & $5.85 \pm 0.71 \mu \mathrm{gl}^{-1}$ \\
EPA & $27.6 \pm 0.3 \mu \mathrm{g} \mathrm{m}^{-1}$ \\
Uronema confervicolum extracts & $26.5 \pm 1.4 \mathrm{~g} \mathrm{ml}^{-1}$ \\
\hline
\end{tabular}

solutions were used as positive reference controls. The lower toxicity was induced by EPA exposure with an $\mathrm{EC}_{50}$ value of $27.6 \mu \mathrm{g} \mathrm{ml} \mathrm{m}^{-1}$.

\section{Short-term experiment}

The oxygen production of the biofilms evolved in 2 different ways during the incubation. In some cases it remained stable, such as for the control, and in others it progressively decreased, such as for the treatment with $1 \mu \mathrm{M}$ diuron (Fig. 1). Oxygen fluxes measured at the beginning of the experiment were between 2.2 and $12.6 \mathrm{nmol} \mathrm{cm}{ }^{-2} \mathrm{~min}^{-1}$ for all the biofilms.

Repeated-measure ANOVA on net oxygen fluxes before and after $2 \mathrm{~h}$ of exposure showed a significant time $\times$ treatment interaction $(p<0.05)$ for some concentrations of all the compounds (Fig. 2A), indicating a significant difference between control and treatment biofilms in terms of oxygen flux evolution. Solutions of diuron from $0.5 \mu \mathrm{M}, \mathrm{DD}$ from $50 \mu \mathrm{g} \mathrm{ml}^{-1}$, EPA from $10 \mu \mathrm{g} \mathrm{ml}^{-1}$ and Uronema confervicolum extracts from $350 \mu \mathrm{g} \mathrm{ml}^{-1}$ had negative effects on the evolution of net oxygen fluxes of biofilms during the experiment. The least active compounds were $U$. confervicolum extracts (no effect at $100 \mu \mathrm{g} \mathrm{ml}^{-1}$ ) followed by DD (no effect at $10 \mu \mathrm{g} \mathrm{ml}^{-1}$ ). At high concentrations of the compounds, inhibition rates of net oxygen fluxes were up to $86 \%$ after $2 \mathrm{~h}$. Treatments had no effect on the depth of the oxygen peak of the microprofiles (data not shown).

The measurement of oxygen profiles every $15 \mathrm{~min}$ allowed us to study the kinetics of net oxygen flux decrease when it occurred (see compounds and concentrations above). This decrease was rapid. On average, for all the treatments inducing a significant effect, $59 \%$ of the total effect was reached within $15 \mathrm{~min}$. The difference between 2 successive measures of the proportion of the $t_{0}$ oxygen flux of biofilms was significantly higher $(p<0.05)$ at 15 min for every treatment inducing a significant effect, except for diuron at $0.5 \mu \mathrm{M}$ (Fig. 3). For this treatment, the net oxygen flux of biofilms increased before a progressive decrease. In treatments that induced a significant effect on oxygen

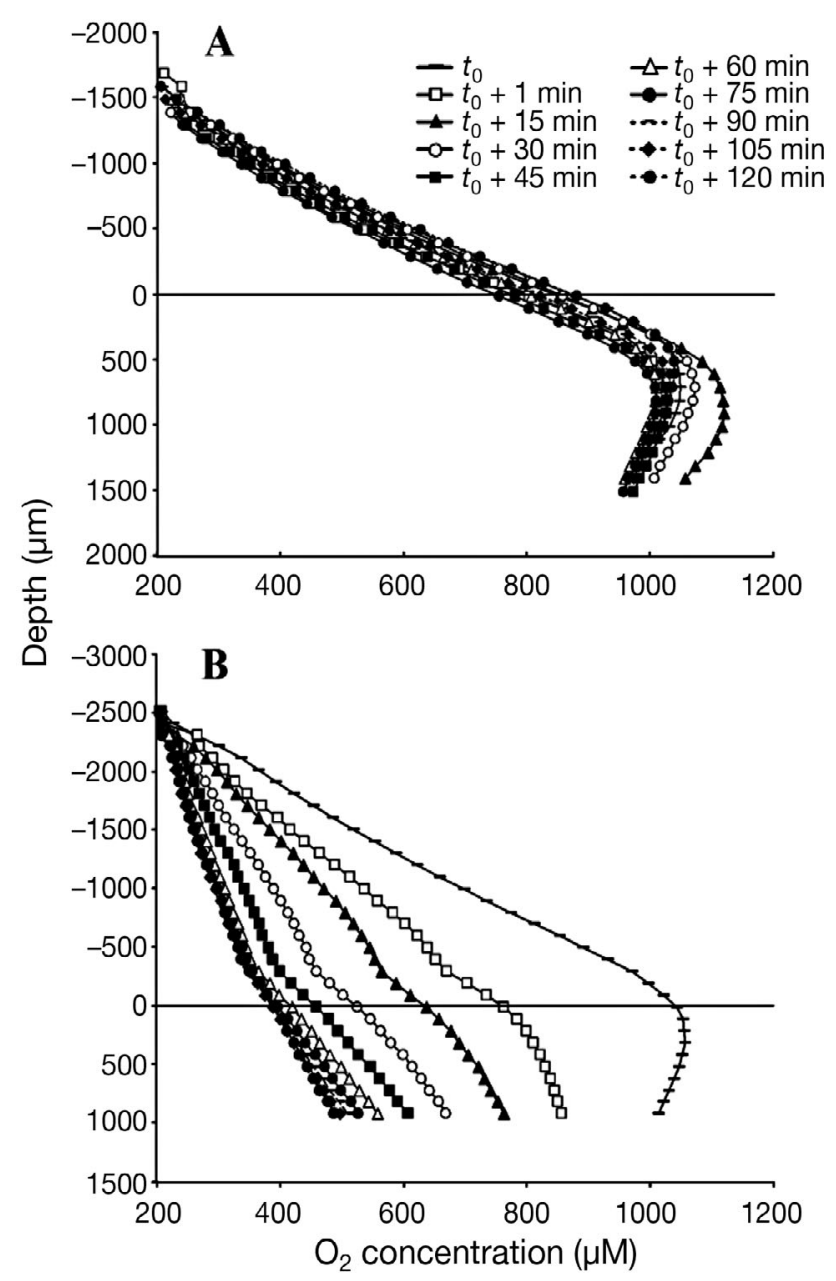

Fig. 1. Short-term experiment. Oxygen microprofiles measured simultaneously every $15 \mathrm{~min}$ for $2 \mathrm{~h}$ at one location for (A) control and (B) treatment exposed to $1 \mu \mathrm{M}$ diuron solution biofilms. Depth $=0 \mu \mathrm{m}$ indicates the biofilm-liquid medium interface; positive values indicate depths in the biofilm and negative values indicate depths in the overlaying liquid medium

flux, there was a significant positive correlation ( $\mathrm{p}<$ $0.05, r^{2}=0.575$ ) between the total effect of treatments (decrease at $120 \mathrm{~min}$ compared with $t_{0}$ ) and the proportion of the effect reached within 15 min (decrease at $15 \mathrm{~min} /$ decrease at $120 \mathrm{~min}$ ). This means that the greater the decrease in oxygen production, the more quickly the decrease appeared. This correlation was much stronger when the average value for the $0.5 \mu \mathrm{M}$ diuron treatment was removed from the data set $(\mathrm{p}<$ $0.001, r^{2}=0.909$ ).

\section{Medium-term experiment}

In this experiment, biofilms were exposed to the same compounds for $3 \mathrm{~d}$. During the incubation period, 

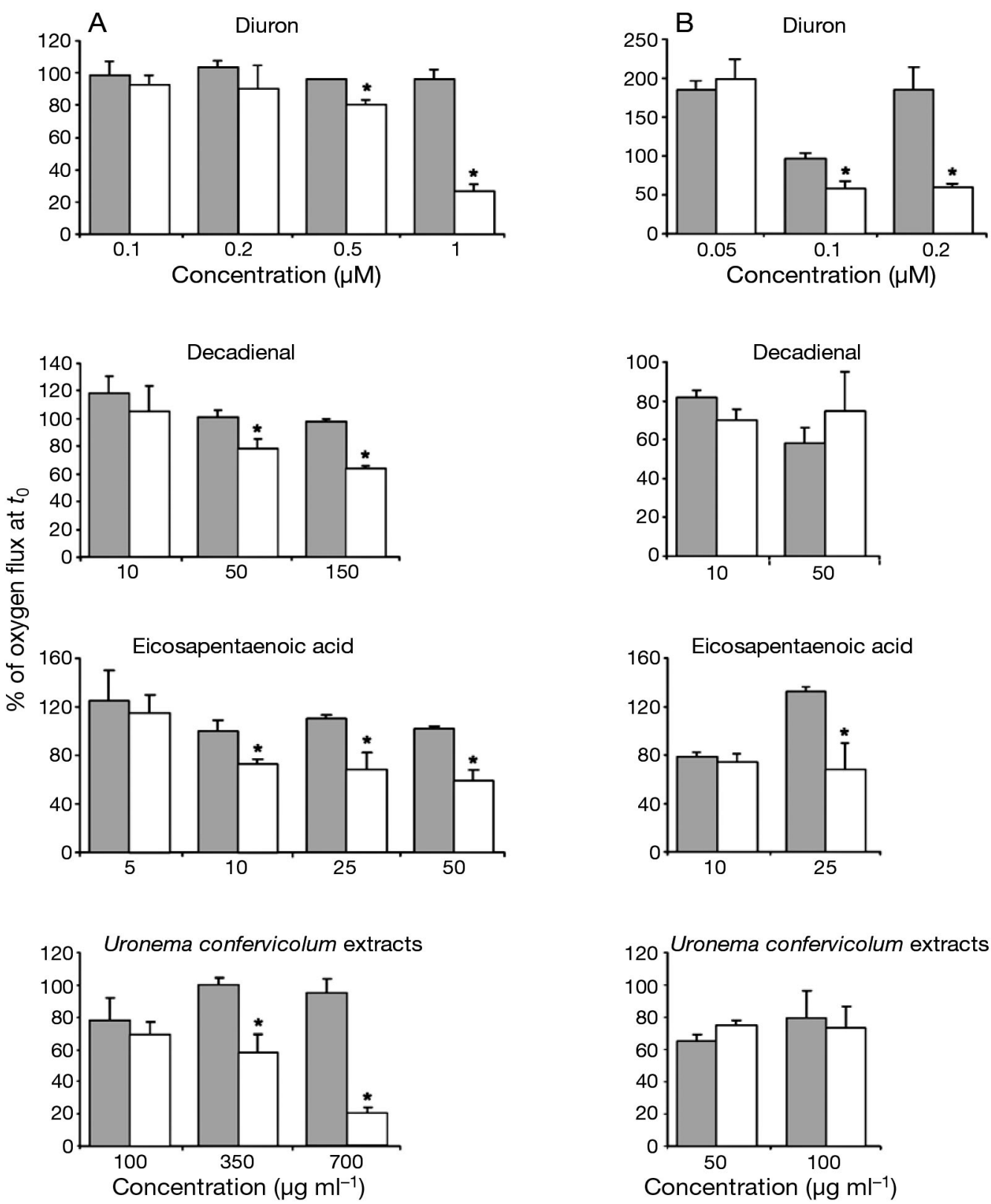

Fig. 2. (A) Short-term experiment and (B) medium-term experiment. Proportions of $t_{0}$ oxygen flux after (A) $2 \mathrm{~h}$ and (B) $3 \mathrm{~d}$ of incubation for control (grey bars) and treatment (white bars) (mean $\pm \mathrm{SE}, 3 \leq \mathrm{n} \leq 5$ ). Asterisks indicate treatments where the interaction time $\times$ treatment was significant (repeated-measure ANOVA on [A] net and [B] mean net oxygen flux values, $p<0.05$ )

the mean net oxygen fluxes either increased or decreased depending on the treatment (Fig. 4). Oxygen fluxes measured were between 2.1 and $12.6 \mathrm{nmol}$ $\mathrm{cm}^{-2} \mathrm{~min}^{-1}$ for all the biofilms.

Repeated-measure ANOVA on mean net oxygen fluxes of the biofilms before and after exposure showed significant time $\times$ treatment interaction $(\mathrm{p}<$ 0.05) for several concentrations of diuron and EPA (Fig. 2B). The DD and Uronema confervicolum extracts had no effect for up to 50 and $100 \mu \mathrm{g} \mathrm{ml}^{-1}$ final concentrations, respectively.

\section{DISCUSSION}

The present study investigated whether the functioning of artificial diatom biofilms could be affected by several natural algal bioactive compounds. We demonstrated that EPA, DD and extracts of the allelopathic green alga Uronema confervicolum significantly decreased net oxygen production of the artificial biofilms.

Data about environmental concentrations of EPA and DD are scarce. A recent study reported EPA con- 


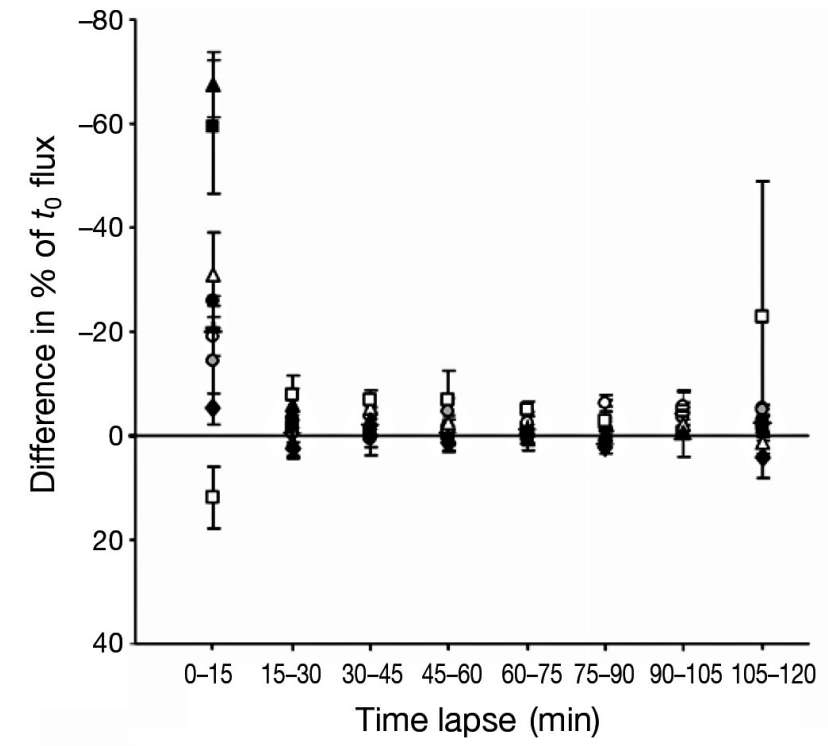

- Diuron $1 \mu \mathrm{M}$ $\square$ Diuron $0.5 \mu \mathrm{M}$ $+\mathrm{DD} 50 \mu \mathrm{g} \mathrm{ml}^{-1}$ - EPA $50 \mu \mathrm{g} \mathrm{ml}^{-1}$
O EPA $25 \mu \mathrm{g} \mathrm{ml}^{-1}$
O EPA $10 \mu \mathrm{g} \mathrm{ml}^{-1}$

A U. c. extracts $700 \mu \mathrm{g} \mathrm{ml}^{-1}$ $\Delta U$. c. extracts $350 \mu \mathrm{g} \mathrm{ml}^{-1}$ - Control

Fig. 3. Short-term experiment. Differences between 2 consecutive values of $t_{0}$ flux proportion for the treatments inducing a significant effect on oxygen flux evolution during incubation and for the controls (mean of all the control biofilms). Negative values indicate a decrease of $t_{0}$ flux proportion and positive values an increase. Vertical bars represent SE. DD: 2E,4E-decadienal; EPA: eicosapentaenoic acid; U. c.: Uronema confervicolum

centrations averaging $0.6 \mu \mathrm{g} \mathrm{ml}^{-1}$ in the extracellular water fraction and $558 \mathrm{\mu g} \mathrm{ml}^{-1}$ in the cell biomass of freshwater diatom biofilms activated by freeze-thaw cycling (Jüttner 2005). The range of EPA concentrations used in the present study, between 5 and $50 \mu \mathrm{g}$ $\mathrm{ml}^{-1}$, seems to be realistic since concentrations of EPA might be high in the vicinity of damaged cells. Moreover, the low distances between cells in dense biofilms could favour the exposure of a great number of intact cells to these concentrations. Considering that EPA cellular contents vary among species (Yongmanitchai \& Ward 1991), it is expected that EPA can occur at higher concentrations in phototrophic biofilms other than those studied by Jüttner (2005). Jüttner (2005) suggested that in extracellular water most EPA was quickly converted into polyunsaturated aldehydes while it remained untransformed in the damaged cells. Total concentration of polyunsaturated aldehydes was $7 \mu \mathrm{M}$ in the extracellular fraction and $23 \mu \mathrm{M}$ in cell biomass. The concentrations of DD tested in this study were higher and ranged from 66 to $990 \mu \mathrm{M}$. A concentration of $7 \mu \mathrm{M}$ of polyunsaturated aldehydes would correspond to $1.1 \mathrm{\mu g} \mathrm{ml}^{-1}$ of DD if it was the only compound present in the solution. The concentrations

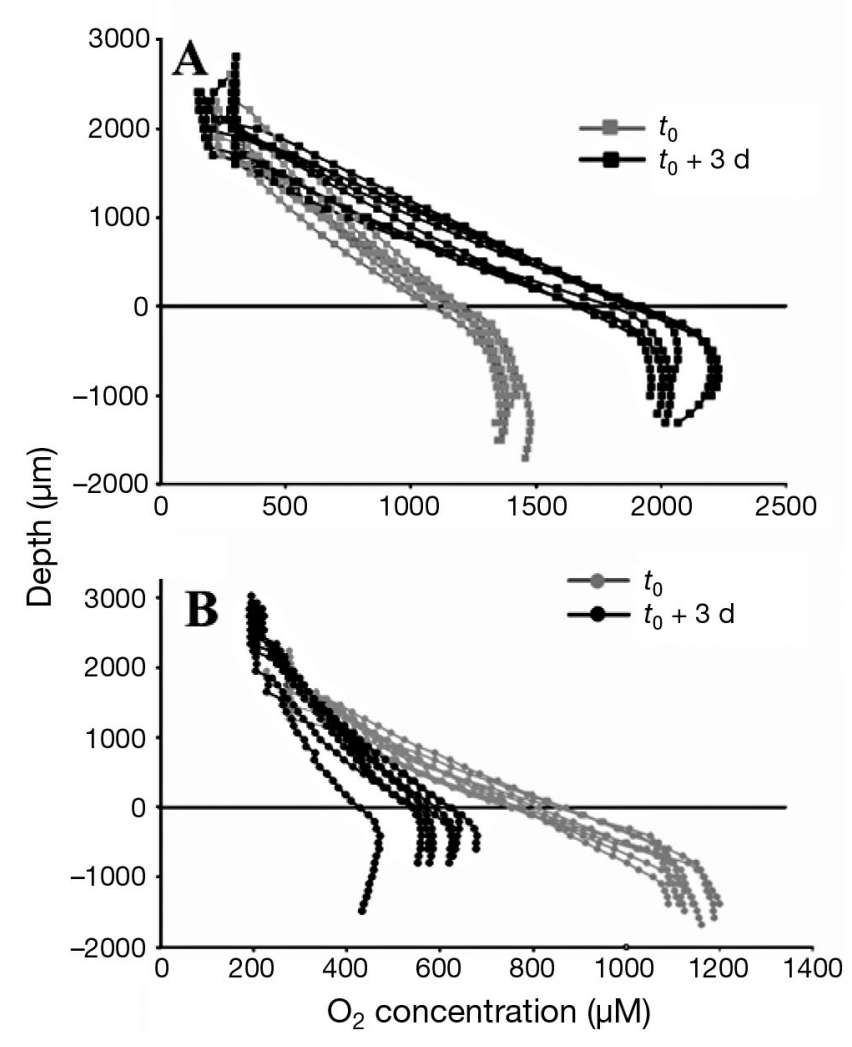

Fig. 4. Medium-term experiment. Oxygen microprofiles measured simultaneously in 8 points of (A) control and (B) treatment biofilms before $\left(t_{0}\right)$ and after $3 \mathrm{~d}$ of incubation $\left(t_{0}+\right.$ $3 \mathrm{~d})$. Treatment biofilm was exposed to diuron at $0.2 \mu \mathrm{M}$. Depth $=0 \mu \mathrm{m}$ indicates the biofilm - liquid medium interface; positive values indicate depths in the biofilm and negative values (preceded with -) indicate depths in the overlaying liquid medium

employed in this study are 1 order of magnitude higher. Nevertheless, it should be noted that we employed DD as a model of polyunsaturated aldehyde. Diatoms can release a wide spectrum of polyunsaturated aldehydes depending on the considered species or strains (Wendel \& Jüttner 1996, Pohnert \& Boland 2002, Pohnert et al. 2002). Some of these aldehydes could be much more active than DD. In that case, effects similar to those observed with DD in the present study could be obtained with other reactive aldehydes at much lower concentrations. Moreover, sensitivity of Nitzschia palea to DD ( $3 \mathrm{~d} \mathrm{EC}_{50}$ value of $5.85 \mu \mathrm{g} \mathrm{ml}^{-1}$ ) was low compared with those described for the marine diatom Thalassiosira weissflogi $\left(24 \mathrm{~h} \mathrm{EC}_{50}\right.$ value of $0.29 \mu \mathrm{g} \mathrm{ml}^{-1}$, Casotti et al. 2005), suggesting that in freshwater environments another aldehyde, perhaps 2E, 4Z, 7Z-decatrienal, may play a more important role than DD. Finally, several active aldehydes may act synergistically.

The $\mathrm{EC}_{50}$ value obtained for Uronema confervicolum extracts may look high compared with those of the 
other compounds. However, concentrations are given for gross extract and not for each pure active compound included in the methanolic extracts. These active compounds are not yet identified; thus, it is difficult to discuss the relevancy of the concentrations. Nevertheless, Nitzschia palea and U. confervicolum shared the same habitat, i.e. they were isolated from the same natural biofilm samples, and thus, were in competition for resources and space. Since $U$. confervicolum extracts have inhibitory properties, it is likely that the 2 algae had allelopathic interactions in their natural environment.

To our knowledge, negative effects of EPA on diatoms have not been previously reported. This compound has been employed as a negative control in marine studies to emphasize the effects of DD (Miralto et al. 1999, Caldwell et al. 2003, 2004). We show that EPA can significantly inhibit both algal growth in liquid culture and net oxygen production in biofilm. Moreover, EPA had a more pronounced effect on oxygen production in biofilm than did DD.

We measured the oxygen community metabolism with microelectrodes to check the effect of toxic compounds on biofilms as performed by Satoh et al. (2005). Our goal was to show that this approach can also be applied successfully for the study of the effect of natural bioactive compounds. The microsensor technique is particularly suitable to detect short-term effects. In this way, we observed that $60 \%$ of the inhibitory effect of net oxygen production occurred within $15 \mathrm{~min}$ for the $2 \mathrm{~h}$ incubations (Fig. 3). The use of microelectrodes provided information about the immediate physiological state of both phototrophic and heterotrophic communities constituting the biofilm. In contrast, the classical ecotoxicological assays showed long-term effects of the compounds on the algae, but in both cases, the exposure time to the compounds was the same (3 d).

Contrasting results were obtained from these 2 approaches, especially for Uronema confervicolum extracts and DD. For these compounds, significant effects on oxygen fluxes have been observed after exposure at some concentrations that were much higher than the concentrations at which Nitzschia palea growth was significantly reduced. The first hypothesis to explain this result is that at these concentrations the compounds affected not only N. palea and its physiology (photosynthesis minus respiration), but also the bacterial community (respiration). The consequence is that no effect could be observed in terms of net oxygen production, although there may have been some effects on the gross photosynthesis and on the respiration. The use of the light-dark shift method (Revsbech et al. 1983), which determines the rates of gross photosynthesis, would be useful to check this hypothesis. Accordingly, it is possible to calculate the oxygen respiration rate in the light by subtracting the net oxygen production rate from the gross production rate. However, this method is more time-consuming and would not have allowed us to follow the fast kinetics of the inhibitory effects. Another hypothesis is that $N$. palea growing in biofilms may have been less affected by the compounds than $N$. palea growing in liquid culture. This might be due either to low penetration of the compound inside the biofilm and adsorption onto the biofilm constituents or to the high cellular density, which reduced the number of molecules per cell. Indeed, it is well known that bacteria in biofilms are more resistant to toxic compounds than are planktonic ones, and cells and the exopolysaccharide matrix contribute to a reduced penetration of the toxic compounds in micro-organisms (Chan et al. 2004, Harrison et al. 2005). Hence, it has been proposed that biofilm constituents can neutralize the toxic compounds (van der Wende et al. 1989) or that differences in bacteria physiological state may be involved. These phenomena are likely to occur in phototrophic biofilms. The 2 hypotheses are not mutually exclusive. These results emphasize the protective properties of biofilms for microbial communities and point out that ecotoxicological studies need to take into account the ecological specificities of algae in their natural environment (e.g. occurrence in both plankton and biofilms) to clearly assess the effects of inhibitors on each species.

The pattern of inhibitory effects differed between the tested compounds. The first difference concerned the relative responses of the artificial biofilms for $2 \mathrm{~h}$ and $3 \mathrm{~d}$ incubations. For diuron, significant decreases in net oxygen productivity rates of biofilms were observed at lower concentrations for $3 \mathrm{~d}$ exposures than for $2 \mathrm{~h}$ exposures. However, the sensitivity of biofilms to DD and EPA, in terms of net oxygen production, decreased when the exposure time increased (Fig. 2). This decrease in sensitivity was not a methodological bias linked to biofilm heterogeneity because it was not observed for diuron. It is probably not linked to microbial degradation of EPA and DD since culture medium containing the compound was renewed a few hours before measurements were taken in the medium-term experiment. Sensitivity to the compounds should have been at least equivalent to those observed for the short-term experiment. It seems, instead, that the diatom could acclimate to the compounds throughout the experiment. To test this hypothesis in future studies, oxygen microprofiles should be measured at the same location in the biofilm for $3 \mathrm{~d}$. This raises the problem of maintaining the biofilms under measurement conditions. The hypothesis of an acclimation to EPA and DD is consistent with the results of Vardi et al. (2006), who demonstrated 
that diatom cells pretreated with DD at low concentrations were less sensitive during a subsequent exposure than were non-pretreated cells. They concluded that, depending on the concentration, DD could either induce a stress response and resistance or cell death. In our experiment, the range of concentrations, though high compared with those of Vardi et al. (2006), was probably under the threshold of death induction. There was no acclimation of oxygen metabolism of the diatom biofilms to diuron exposures.

Another difference between the observed compound effects concerned the relative sensitivity of Nitzschia palea in cell suspension or in biofilm. Indeed, diuron and particularly EPA decreased the net oxygen production rate of artificial biofilms at concentrations close to $\mathrm{EC}_{50}$ value, while $\mathrm{DD}$ and Uronema confervicolum extracts had no effect on oxygen fluxes in biofilms at the $\mathrm{EC}_{50}$ concentrations, regardless of exposure time. EPA also differed in the way it induced a negative effect on the net oxygen production rate in biofilms at a concentration 2.75 times below the corresponding $\mathrm{EC}_{50}$ value. Moreover, $N$. palea was less sensitive to EPA than to DD in cell suspension while biofilms were more sensitive to EPA. This could be explained by differences in bioavailability of the compounds inside the biofilm, by possible bacterial transformation of EPA into a more active compound or by differential effects of EPA and DD on the bacterial community. The second hypothesis could be envisaged for the medium-term experiment only, since in the short-term experiment the rapid effect observed (see Fig. 3) could not be attributed to bacterial compound degradation. These results emphasize the fact that data obtained from algal cell suspension experiments do not allow a prediction of the effects on algae in biofilm; both contexts should be taken into account for studying the role of biochemical compounds on benthic microalgae.

The main result of this study is that biofilm functioning is significantly affected, at least in terms of net oxygen production, by several natural algal compounds. In addition to direct cell death, the presence of grazers may indirectly affect intact cells by activating the production of the bioactive compounds EPA and DD. Moreover, Vardi et al. (2006) indicated that the stress induced by DD was communicable to neighbouring cells. This could amplify the indirect effects of grazing. Given the mechanism of biofilm acclimation to DD and EPA observed in the medium-term experiment, the negative effect of EPA and DD on biofilm is likely to occur at transitional periods, when grazing activity appears or increases. The presence of these compounds may also have an effect on biofilm composition since the sensitivity to EPA and DD may be speciesdependent.
To our knowledge, the effect of allelopathic compounds on phototrophic biofilm functioning, described here by oxygen turnover, was studied here for the first time. We showed that the presence of an allelopathic alga may have a negative effect on the net oxygen production of a biofilm, either through the exudation of allelopathic compounds or through cell lysis. Up to now the effect of the presence of such alga has been considered only in terms of biofilm specific composition and not in terms of biofilm functioning.

Future studies could focus on synergetic effects of algal products since they may be present together in the environment, especially EPA and DD, which belong to the same synthesis pathway.

Acknowledgements. We thank Y. Nicaise for technical assistance and Jean-Luc Rols. This study was partly funded by the French national network on biofilm research (BIOFILMSPNIR CNRS). We also thank the 2 anonymous referees and the editor for their constructive comments, which helped to improve the manuscript.

\section{LITERATURE CITED}

Becher PG, Jüttner F (2005) Insecticidal compounds of the biofilm-forming cyanobacterium Fischerella sp. (ATCC 43239). Environ Toxicol 20:363-372

> Berard A, Dorigo U, Mercier I, Becker-van Slooten K, Grandjean D, Leboulanger C (2003) Comparison of the ecotoxicological impact of the triazines Irgarol 1051 and atrazine on microalgal cultures and natural microalgal communities in Lake Geneva. Chemosphere 53:935-944

Caldwell GS, Bentley MG, Olive PJW (2003) The use of a brine shrimp (Artemia salina) bioassay to assess the toxicity of diatom extracts and short chain aldehydes. Toxicon 42:301-306

Caldwell GS, Bentley MG, Olive PJW (2004) First evidence of sperm motility inhibition by the diatom aldehyde 2,E-4,Edecadienal. Mar Ecol Prog Ser 273:97-108

> Cannell R (1993) Algae as source of biologically active products. Pestic Sci 39:147-153

Casotti R, Mazza S, Brunet C, Vantrepotte V, Ianora A, Miralto A (2005) Growth inhibition and toxicity of the diatom aldehyde 2-trans, 4-trans-decadienal on Thalassiosira weissflogii (Bacillariophyceae). J Phycol 41:7-20

> Chan C, Burrows LL, Deber CM (2004) Helix induction in antimicrobial peptides by alginate in biofilms. J Biol Chem 279:38749-38754

> Dobretsov S, Dahms HU, Quian PY (2004) Antilarval and antimicrobial activity of waterborne metabolites of the sponge Callyspongia (Euplacella) pulvinata: evidence of allelopathy. Mar Ecol Prog Ser 271:133-146

Epping EHG, Khalili A, Thar R (1999) Photosynthesis and the dynamics of oxygen consumption in a microbial mat as calculated from transient oxygen microprofiles. Limnol Oceanogr 44:1936-1948

Garcia H, Gordon LI (1992) Solubility of oxygen at different temperature and salinity. Limnol Oceanogr 37:1307-1312

Glud NR, Ramsing BN, Revsbech NP (1992) Photosynthesis and photosynthesis-coupled respiration in natural biofilms quantified with oxygen microsensors. J Phycol 28:51-60

> Gross EM (2003) Allelopathy of aquatic autotrophs. Crit Rev 
Plant Sci 22:313-339

Guasch H, Paulsson M, Sabater S (2002) Effect of copper on algal communities from oligotrophic calcareous streams. J Phycol 38:241-248

Hansen E, Eilersten HC (2007) Do the polyunsaturated aldehydes produced by Phaeocystis pouchetii (Hariot) Lagerheim influence diatom growth during the spring bloom in Northern Norway? J Plankton Res 29:87-96

Harrison JJ, Turner RJ, Ceri H (2005) Persister cells, the biofilm matrix and tolerance to metal cations in biofilm and planktonic Pseudomonas aeruginosa. Environ Microbiol 7:981-994

Höckelmann C, Moens T, Jüttner F (2004) Odor compounds from cyanobacterial biofilms acting as attractant and repellents for free-living nematodes. Limnol Oceanogr 49:1809-1819

Ianora A, Miralto A, Poulet AA, Carutenuto Y and others (2004) Aldehyde suppression of copepod recruitment in blooms of a ubiquitous planktonic diatom. Nature 429: 403-407

Jüttner F (1999) Allelochemical control of natural photoautotrophic biofilms. In: Keevil CW, Godfree A, Holt D, Dow C (eds) Biofilms in aquatic environment. R Soc Chem, Cambridge, p 43-50

Jüttner F (2001) Liberation of 5,8,11,14,17-eicosapentaenoic acid and other polyunsaturated fatty acid from lipids as a grazer defense reaction in epilithic diatom biofilm. J Phycol 37:744-755

Jüttner F (2005) Evidence that polyunsaturated aldehydes of diatom are repellents for pelagic crustacean grazers. Aquat Ecol 39:271-282

Jüttner F, Dürst U (1997) High lipoxygenase activities in epilithic biofilms of diatoms. Arch Hydrobiol 138:451-463

Jüttner F, Wu JT (2000) Evidence of allelochemical activity in subtropical cyanobacterial biofilms of Taiwan. Arch Hydrobiol 147:505-517

Kilham SS, Kreeger DA, Lynn SG, Goulden CE, Herrera L (1998) COMBO: a defined freshwater culture medium for algae and zooplankton. Hydrobiologia 377:147-159

Kitano M, Matsukawa R, Karube I (1997) Changes in eicosapentaenoic acid content of Navicula saprophila, Rhodomonas salina and Nitzschia sp. under mixotrophic conditions. J Appl Phycol 9:559-563

Kühl M, Glud NR, Ploug H, Ramsing BN (1996) Microenvironmental control of photosynthesis and photosynthesiscoupled respiration in an epilithic cyanobacterial biofilm. J Phycol 32:799-812

Lange-Berthalot H (2001) Navicula sensu stricto - 10 genera separated from Navicula sensu lato Frustulia, Vol 2. A.R.G. Gantner Verlag K.G., Ruggell

Leflaive J, Ten-Hage L (2007) Algal and cyanobacterial secondary metabolites in freshwaters: a comparison of allelopathic compounds and toxins. Freshw Biol 52:199-214

Leflaive J, Lacroix G, Nicaise Y, Ten-Hage L (2008) Colony induction and growth inhibition in Desmodesmus quadrispina (Chlorococcales) by allelochemicals released from the filamentous alga Uronema confervicolum (Ulotrichales). Environ Microbiol 10:1536-1546

Liess A, Hillebrand H (2004) Direct and indirect effects in herbivore-periphyton interactions. Arch Hydrobiol 159: 433-453

McCormick PV (1996) Resource competition and species coexistence in freshwater benthic algal assemblages. In: Stevenson R, Bothwell M, Lowe R (eds) Algal ecology: freshwater benthic ecosystems. Academic Press, San Diego, CA, p 229-252
Metaxas A, Lewis AG (1991) Copper tolerance of Skeletonema costatum and Nitzschia thermalis. Aquat Toxicol 19:265-280

> Miralto A, Barone G, Romano G, Poulet AA and others (1999) The insidious effect of diatoms on copepod reproduction. Nature 402:173-176

> Patterson GML, Larsen LK, Moore RE (1994) Bioactive natural products from blue-green algae. J Appl Phycol 6:151-157

Pohnert G (2000) Wound-activated chemical defense in unicellular planktonic algae. Angew Chem Int Ed 39: $4352-4354$

Pohnert G (2002) Phospholipase A2 activity triggers the wound-activated chemical defense in the diatom Thalassiosira rotula. Plant Physiol 129:103-111

Pohnert G, Boland W (2002) The oxylipin chemistry of attraction and defense in brown algae and diatoms. Nat Prod Rep 19:108-122

Pohnert G, Lumineau O, Cueff A, Adolph S, Cordevant C, Lange M, Poulet S (2002) Are volatile unsaturated aldehydes from diatoms the main line of chemical defense against copepods? Mar Ecol Prog Ser 245:33-45

Pohnert G, Steinke M, Tollrian R (2007) Chemical cues, defence metabolites and the shaping of pelagic interspecific interactions. Trends Ecol Evol 22:198-204

Revsbech NP (1989) An oxygen microsensor with a guard cathode. Limnol Oceanogr 34:474-478

Revsbech NP, Jorgesen BB, Blackburn TH (1983) Microelectrode studies of the photosynthesis and $\mathrm{O}_{2}, \mathrm{H}_{2} \mathrm{~S}$ and $\mathrm{pH}$ profiles of a microbial mat. Limnol Oceanogr 28: $1062-1074$

Rice EL (1984) Allelopathy, 2nd edn. Academic Press, New York

Rohr JR, Crumrine PW (2005) Effects of an herbicide and an insecticide on pond community structure and processes. Ecol Appl 15:1135-1147

> Roussel H, Ten-Hage L, Joachim S, Le Cohu R, Gauthier L, Bonzom JM (2007) A long-term copper exposure on freshwater ecosystem using lotic mesocosms: primary producer community responses. Aquat Toxicol 81:168-182

Satoh H, Sasaki Y, Nakamura Y, Okabe S, Suzuki T (2005) Use of microelectrodes to investigate the effects of 2chlorophenol on microbial activities in biofilms. Biotechnol Bioeng 91:133-138

Sterner RW (1989) Resource competition during seasonal succession toward dominance by cyanobacteria. Ecology 70:229-245

Stevenson R (1996) An introduction to algal ecology in freshwater benthic habitats. In: Stevenson R, Bothwell M, Lowe $\mathrm{R}$ (eds) Algal ecology - freshwater benthic ecosystems. Academic Press, San Diego, CA, p 3-30

van der Wende E, Characklis WG, Smith DB (1989) Biofilms and bacterial drinking water quality. Water Res 23:1313-1322

Vardi A, Formiggini F, Casotti R, De Martino A, Ribalet F, Miralto A, Bowler C (2006) A stress surveillance system based on calcium and nitric oxide in marine diatoms. PLoS Biol 4(3):e60

Wendel T, Jüttner F (1996) Lipooxygenase-mediated formation of hydrocarbons and unsaturated aldehydes in freshwater diatoms. Phytochemistry 41:1445-1449

> Wolfe GV (2000) The chemical defense ecology of marine unicellular plankton: constraints, mechanisms, and impacts. Biol Bull (Woods Hole) 198:225-244

- Yongmanitchai W, Ward OP (1991) Screening of algae for potential alternative sources of eicosapentaenoic acid. Phytochemistry 30:2963-2967 